\title{
CLINICAL PROFILE AND MANAGEMENT OF PATIENTS OF AMOEBIC LIVER ABSCESS IN A TERTIARY CARE CENTRE
}

\section{Medicine}

Dr. Rakesh Mishra

MD Medicine, Senior Resident, Department of Medicine, Command Hospital(EC), Alipore, Kolkata.

$\begin{array}{ll}\begin{array}{l}\text { Dr.Debabrata } \\ \text { Banerjee }\end{array} & \text { MD, DM (Gastroenterology), Professor, Department of Medicine, Command Hospital } \\ \end{array}$

Dr.Debarshi Jana* Young Scientist, IPGMER and SSKM Hospital, Kolkata.*Corresponding Author

\section{ABSTRACT}

Introduction: Amoebiasis is caused by the protozoan Entamoeba histolytica. Most infections are asymptomatic; clinical manifestations include amoebic dysentery and extra intestinal disease. Amoebic liver abscess is the most common extraintestinal manifestation of amoebiasis. Amoebae establish hepatic infection by ascending the portal venous system.

Aim: To study various aspects of Amoebic Liver Abscess like demographic profiles, clinical presentations, association with intestinal disease, radiological and laboratory findings, treatment modalities and complications.

Materials and Methods: A hospital based prospective observational study was performed in the Department of Internal Medicine, Command Hospital (Eastern Command), Kolkata, from Jan 2018 to Jun 2019. All confirmed cases of amoebic liver abscess above the age of 18 years admitted in Command Hospital (EC) were included in this study. The patient were then subsequently followed up for 01 year with USG abdomen every 03 monthly.

Results: Total 40 patients of Amoebic Liver Abscess with age more than 18 year were enrolled in the study. The age ranged from 26 to 70 years (mean age 46.2 year). Male patients were dominated over female. $80.0 \%$ were from rural background. About $55 \%$ patients were addicted to alcohol \& $25.0 \%$ were known diabetics at presentation. In all, $07(17.5 \%$ ) patients with abscess size of $6 \mathrm{~cm}$ to $10 \mathrm{~cm}$ (Vol>300 cc) were treated by needle aspiration and drug therapy. Remaining $17(42.5 \%)$ patients with abscess size more than $10 \mathrm{~cm}$ were treated with pigtail drainage and drug.

Conclusion: There is significant advantage of pigtail drainage with drug treatment over needle aspiration with drug and only with drug treatment in terms of decrease in lesion size and early recovery.

\section{KEYWORDS}

\section{Amoebic Liver Abscess, Clinical Profile, Management}

\section{INTRODUCTION}

Liver is the most common organ which is prone to development of abscess, contributing about $48 \%$ of all visceral abscess and $13 \%$ of all intra-abdominal abscess. Liver abscess fall broadly into two categories- amoebic and pyogenic. Pyogenic Liver Abscess (PLA) is more common in developed world, while Amoebic Liver Abscess (ALA) is more common in developing world.

ALA is the commonest extra intestinal manifestation of amoebiasis which arises due to spread of Entamoeba histolytica from the large bowel to the liver via the portal vein. Entamoeba histolytica infects $10 \%$ of world population, out of which $10 \%$ develop invasive amoebiasis and $1-10 \%$ of them develop ALA. Most of the infected persons reside in tropical and subtropical countries like tropical Asia, Africa, Mexico, Central and South America.

In developing countries, amoebiasis is more common due to poor sanitary conditions and lower socioeconomic status. Other predisposing factors for ALA are alcoholism, homosexuality and individuals with AIDS or immunosuppression. In developed countries, amoebic liver abscess is rare and is found almost exclusively in travellers and immigrants.

ALA presents itself more commonly with fever and right upper quadrant pain. There may be uncommon manifestations due to rupture of abscess in neighbouring cavities like pleura, pericardium and peritoneum, compression of tubular structures in hepatic hilum and distant embolic dissemination. Ultrasonography is the method of choice for diagnosis of liver abscess. ALA should be further confirmed by microscopic examination of pus for amoebic trophozoites and detection of serum anti-amoebic IgG antibody by Enzyme Linked Immunosorbent Assay (ELISA). Although, the presence of amoebic trophozoites in aspirated pus is confirmatory for ALA, it is not a sensitive method of diagnosis. So, detection of serum anti-amoebic antibody is the most frequently used for its diagnosis. Early diagnosis and treatment of ALA is essential as it results in low morbidity and mortality.

This study will be carried out to look for various aspects of ALA like demographic profile, clinical presentations, association with intestinal disease, radiological and laboratory findings, treatment modalities and complications.

\section{Aims}

To study various aspects of Amoebic Liver Abscess like demographic profiles, clinical presentations, radiological and laboratory findings, treatment modalities and complications.

\section{MATERIALSAND METHODS}

1.STUDY DESIGN:

Study Area: Department of Internal Medicine, Command Hospital (Eastern Command), Kolkata.

Study Period: The study was conducted from Jan 2018 to Jun 2019

Study Population: The study was carried out on all confirmed cases of Amoebic liver abscess admitted in Command Hospital (EC). Informed consent was taken from all the patients.

Sample Size: All consecutive patients admitted during the study period. A total of 40 patients were included during the study period. Study Type: Prospective observational study.

\section{INCLUSION CRITERIA}

- All confirmed cases of Amoebic liver abscess, 18 yrs or above admitted in Command Hospital (EC),Kolkata.

\section{EXCLUSION CRITERIA}

- Hydatid cyst of liver, solid masses of liver, primary and secondary malignancies of liver.

- Pyogenic liver abscess

- Age less than 18 yrs.

\section{STATISTICALANALYSIS}

For statistical analysis data were entered into a Microsoft excel spreadsheet and then analyzed by SPSS 24.0. and Graph Pad Prism version 5. Data had been summarized as mean and standard deviation for numerical variables and count and percentages for categorical variables.

\section{RESULTS AND ANALYSIS}

We found that total of 40 clinically and ultrasonographically probable cases of amoebic liver abscess were included in the study, confirmed on the basis of positive serum IgG ELISA for E.histolytica. These 40 patients were further investigated and described underneath. The age of the study subjects ranged between 26 years to 70 years, with the mean age being 46.2 years. The age group $41-60$ years comprised the maximum cases $(60.0 \%)$. The ratio of male to female was 19:1. About 
$55.0 \%$ patients had a history of alcoholism and $25.0 \%$ were diabetic. $80.0 \%$ of the patient were from rural background.

We showed total 30 patients $(75.0 \%)$ presented with acute signs and symptoms (within 14 days), (4/40) $10.0 \%$ patients had sub- acute (within 15-30 days), while (6/40) $15.0 \%$ patients had chronic presentations $(>30$ days).Fever $40(100.0 \%)$ and upper abdominal pain $36(90.0 \%)$ were the most common symptoms. Hepatomegaly $(>14 \mathrm{~cm}$ liver span) was seen in $28(70.0 \%)$ cases. Jaundice and ascites were seen in $04(10.0 \%)$ and $02(5.0 \%)$ of cases respectively. Pleural effusion was the commonest complication seen in $12(30.0 \%)$ of cases

Our study showed that the right lobe was involved in $30(75.0 \%)$ cases, left lobe in $8(20.0 \%)$ cases and both the lobes were involved in 2 $(5.0 \%)$ cases. Most of the abscess $34(85.0 \%)$ were solitary in nature and out of which right lobe was involved in $65.0 \%$ cases. Volume of abscess ranged between $9.64 \mathrm{cc}$ and as much as $1317.12 \mathrm{cc}$ with the mean volume as $511.26 \mathrm{cc}$. Volume less than $300 \mathrm{cc}$ was seen in 16 cases $(40.0 \%)$ and more than $300 \mathrm{cc}$ was seen in 24 cases $(60.0 \%)$. Size of the lesion $<6.0 \mathrm{~cm}$ seen in $6(15.0 \%), 6-10 \mathrm{~cm}$ in $17(42.5 \%)$ and $>$ $10.0 \mathrm{~cm}$ in $17(42.5 \%)$ of cases. Pleural effusion was the major complications found in $30.0 \%$ of patients in this study.

We found anemia and leukocytosis were the most common hematological findings seen in 30(75.0\%) cases. Increased Alkaline Phosphatase (ALP) was seen in $40.0 \%$ cases. Amoebic serology (IgG ) was done in all the patients and was found to be positive in $38(95.0 \%)$ of the cases(in other 02 cases negative result was probably due to testing within 07 days of presentation). $10 / 40(25.0 \%)$ of cases had raised bilirubin level out of which $4 / 40(10.0 \%)$ also had prolonged Prothrombin time. Raised ALT and AST were seen in 12(30.0\%) and $24(60.0 \%)$ of the patients. Hypoalbuminaemia was seen in $26(65.0 \%)$ cases, 10/40(25\%) marked Hypoalbuminaemia (Serum Alb < $2.5 \mathrm{mg} / \mathrm{dL}$ ), 16/40(40\%) mild Hypoalbuminaemia (Serum Alb: 2.5 $3.5 \mathrm{mg} / \mathrm{dL}$ )

We showed that the Ultrasonographically, the size of abscess was in the range of $2.5 \mathrm{~cm}$ to $14 \mathrm{~cm}$. About $16(40.0 \%)$ patients had abscess size volume less than $300 \mathrm{cc}$ and were treated by drug therapy only $(800 \mathrm{mg}$ metronidazole three times in a day). In all, $07(17.5 \%)$ patients with abscess size of $6 \mathrm{~cm}$ to $10 \mathrm{~cm}$ ( Vol $>300 \mathrm{cc}$ ) were treated by needle aspiration and drug therapy. Remaining $17(42.5 \%)$ patients with abscess size more than $10 \mathrm{~cm}$ were treated with pigtail drainage and drug.

Our study showed that the cases were followed up with serial USG abdomen at 03 month, 06 month and after 01 year. There was significant decrease in mean size of the lesion observed after 12 months, $71.65 \%$ in pigtail drainage with drug vs $67.0 \%$ in Needle aspiration with drug vs $43.02 \%$ in only drug group with corresponding decrease in mean volume as $97.02 \%, 94.29 \% \& 71.9 \%$ respectively (pValue $<0.001)$

\section{DISCUSSION}

Liver is the most common organ which is prone to development of abscess, contributing about $48 \%$ of all visceral abscess and $13 \%$ of all intra-abdominal abscess. Liver abscess fall broadly into two categories- amoebic and pyogenic. Pyogenic Liver Abscess (PLA) is more common in developed world, while Amoebic Liver Abscess (ALA) is more common in developing world.

ALA is the commonest extra intestinal manifestation of amoebiasis which arises due to spread of Entamoeba histolytica from the large bowel to the liver via the portal vein. Entamoeba histolytica infects $10 \%$ of world population, out of which $10 \%$ develop invasive amoebiasis and $1-10 \%$ of them develop ALA. Most of the infected persons reside in tropical and subtropical countries like tropical Asia, Africa, Mexico, Central and South America. ALA can be suspected in any person of endemic region who presents with fever, pain abdomen and liver tenderness

The mean age of patients in our study was 46.20 years which was in accordance with Indian studies, Ghosh et al, Sharma et al, Mukhopadhyay et al and Jain V et al who reported it to be 41, 40.5, 43.64 and 41.8 years, respectively. ${ }^{2.5}$

As far as sex predisposition was concerned, after recruiting 40 consecutive patients, only 02 patients were female. Indian data show predominant male involvement; Sharma et al, Mukhopadhyay et al and Ghosh et al reported male to female ratio to be 7:1,11:1 and 14.38:1

\section{respectively.}

Various theories have been postulated to explain this gender difference but the exact reason is still not known. Researchers have tried to explain the alcohol consumption in men, hormonal influences in premenopausal women ${ }^{6}$ protective effect of iron deficiency anaemia among menstruating women, as some of the reasons for males being affected more than females.

In present study alcohol consumption was seen as a major risk factor as $55.0 \%$ patients of ALA were exposed to it. Jain V et al \& Ghosh et al had $58.4 \%$ \& $72 \%$ alcoholic patients in their study respectively. Alcohol suppresses function of Kupffer cells (specialized macrophage) in liver which has important role in clearing amoeba. Moreover, invasive amoebiasis appears to be dependent on the availability of free iron. A high content of iron in the diet, often obtained from the country liquor in habitual drinkers predisposes to invasive amoebiasis, as does a diet rich in carbohydrate.

Low iron levels in females belonging to low socioeconomic families, have inhibitory effect to Entamoeba histolytica growth.

Singh $\mathrm{R}$ et al also found that intervention combined with anti-amoebic therapy hasten the recovery. ${ }^{10} \mathrm{He}$ did a prospective randomized comparative study of 60 patients, presented in outpatient and emergency department at Dr Ram Manohar Lohia Hospital ,Delhi, randomized equally into two groups, percutaneous needle aspiration and pigtail catheter drainage. The effectiveness of either treatment was measured in terms of duration of hospital stay, days to achieve clinical improvement, $50 \%$ reduction in abscess cavity size and total $/$ near total resolution of abscess cavity. Independent t-test was used to analyze these parameters.

The success rate was significantly better in catheter drainage group $(\mathrm{P}=0.006)$. The patients in pigtail catheter drainage group showed earlier clinical improvement $(\mathrm{P}=0.039)$ and $50 \%$ decrease in abscess cavity volume $(\mathrm{P}=0.000)$ as compared to those who underwent percutaneous needle aspiration.

Most of the patients in this study presented with uncomplicated liver abscess. Complicated cases and patients with large abscesses were immediately managed by percutaneous intervention. So, no mortality was seen in this study.

\section{CONCLUSION}

- In endemic countries, ALA should always be diagnosis of exclusion particularly in a male patient of low socioeconomic status presenting with abdominal pain, fever and hepatomegaly.

- Right lobe is involved in most of the cases.

- Although, primary focus of infection in ALA is intestine, few cases present themselves with active intestinal infection.

- Immediate proper management must be done to prevent morbidity and mortality.

- There is significant advantage of pigtail drainage with drug treatment over needle aspiration with drug and only with drug treatment in terms of decrease in lesion size and it hastens the recovery.

Table: Socio-demographic profile of patients with ALA

\begin{tabular}{|c|c|c|}
\hline Variables & Number $(\mathrm{n}=40)$ & Percentage (\%) \\
\hline Age Groups (in years) & & \\
\hline $21-30$ & 02 & 5.0 \\
\hline $31-40$ & 10 & 25.0 \\
\hline $41-50$ & 12 & 30 \\
\hline $51-60$ & 12 & 30 \\
\hline $60-70$ & 04 & 10 \\
\hline Sex & & \\
\hline Male & 38 & 95 \\
\hline Female & 02 & 05 \\
\hline Education Status & & \\
\hline Till primary school & 14 & 35.0 \\
\hline Till higher secondary & 24 & 60.0 \\
\hline Graduate & 02 & 5.0 \\
\hline Occupation & & \\
\hline Salaried & 26 & 65.0 \\
\hline Self-employed & 12 & 30.0 \\
\hline Unemployed & 02 & 5.0 \\
\hline
\end{tabular}




\begin{tabular}{|c|c|c|}
\hline Residence & & \\
\hline Rural & 32 & 80.0 \\
\hline Urban & 08 & 20.0 \\
\hline Risk Factors & & \\
\hline Alcohol & 18 & 45.0 \\
\hline Alcohol + Diabetes & 04 & 10.0 \\
\hline Diabetes & 06 & 15.0 \\
\hline Nil & 12 & 30.0 \\
\hline
\end{tabular}

Table: Symptoms, signs and complications ALA

\begin{tabular}{|c|c|c|}
\hline Variables & Number $(n=40)$ & Percentage (\%) \\
\hline \multicolumn{3}{|l|}{ Duration } \\
\hline 1 week & 8 & 20.0 \\
\hline 2 weeks & 22 & 55.0 \\
\hline 3 weeks & 4 & 10.0 \\
\hline$>3$ weeks & 6 & 15.0 \\
\hline \multicolumn{3}{|l|}{ Symptoms } \\
\hline Only Fever & 04 & 10.0 \\
\hline Fever + Upper abdominal pain & 36 & 90.0 \\
\hline Nausea/Vomiting & 04 & 10.0 \\
\hline Anorexia & 36 & 90.0 \\
\hline Diarrhoea & 0 & 0 \\
\hline Cough & 04 & 10.0 \\
\hline \multicolumn{3}{|l|}{ Signs } \\
\hline Fever $(>38 \quad \mathrm{C})$ & 40 & 100.0 \\
\hline Abdominal Tenderness & 40 & 100.0 \\
\hline Hepatomegaly & 28 & 70.0 \\
\hline Jaundice & 4 & 10.0 \\
\hline Ascites & 02 & 5.0 \\
\hline \multicolumn{3}{|l|}{ Complications } \\
\hline Pleural Effusion & 12 & 30.0 \\
\hline Peritonitis & 0 & 0 \\
\hline
\end{tabular}

\section{REFERENCE}

Aikat BK, Bhusnurmath SR, Pal AK, et al. The pathology and pathogenesis of fatal hepatic amoebiasis-A study based on 79 autopsy cases. Trans R Soc Trop Med Hyg $1979 \cdot 73: 188$

2. Ghosh S, Sharma S, Gadpayle AK, Gupta HK, Mahajan RK, Sahoo R, et al. Clinical, Laboratory, and Management Profile in Patients of Liver Abscess from Northern India. J Trop Med. 2014;2014:1423-82

3. Sharma N, Sharma A, Varma S, Lal A, Singh V. Amoebic liver abscess in the medical emergency of a North Indian hospital. BMC research notes. 2010;3(1):21

4. Mukhopadhyay M, Saha AK, Sarkar A, Mukherjee S. Amoebic liver abscess: presentation and complications. Indian J Surg. 2010;72(1):37-41

5. Jain, V., S. Manjavkar, and P. Kapur. "Durfishan., Rajput D, Mir T. Clinical and biochemical profile of liver abscess patients." Int J Res Med Sci 5 (2017): 2596.

6. Shandera WX, Bollam P, Hashmey RH, et al. Hepatic amebiasis among patients in a public teaching hospital. South Med J 1998;91(9):829-37.

7. Hoffner RJ, Kilaghbian T, Esekogwu VI, et al. Common presentations of amebic liver rofmer

8. Makkar RP, Sachdev GK, Malhotra V. Alcohol consumption, hepatic iron load and the risk of amoebic liver abscess: a case-control study. Intern Med. 2003;42(8):644-9

9. Cruz-Castaneda A, López-Casamichana M, Olivares-Trejo JJ. Entamoeba histolytica secretes two haem-binding proteins to scavenge haem. Biochem J. 2011;434(1):10.

10. Singh R, Adhikari DR, Patil BP, Talathi NR, Hanamshetti SR, Joshi RM. Amoebic liver abscess: an appraisal. Int Surg. 2011;96(4):305-09. 